\title{
關於相對論底哲學方面的問題
}

\section{B. 施切爾恩}

列密敉䢘我們，應該把物理學研究的結果興 從通些結果中作出來的哲學結論區分開來。由此 可見，那些把相對論底成就當作反對唯物主義㩑

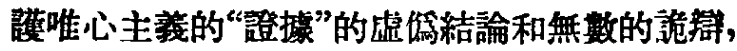

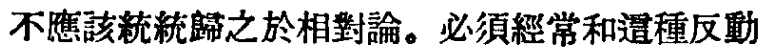

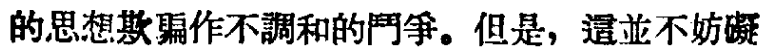
我們㗄立地、批判地研究相對諭底招學內容.

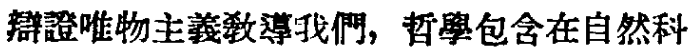
鲆之中，也包含在一切科學之中。逽一點在相對 䤅中達到了極高的高度, 表現得如此明顯, 以至 於誰也不敢來反對。如果找們自己不先翡清楚包 含於相對論中的哲學的特性，我們便不能足够徹 底地消除把唯心主義濫帶進相對論中去的情况。 同時, 篇了有可能去概括這一理論底結果, 以求 淮一步發展我們的世界觀，刻樣做也是必要的。 但是，如果我們打算根據讋登唯物主義底観點來 研究相對論的話, 我們便要㒒可能在相對論的物 理內容與哲學內容之間作一區分。物體在運動的 時候是不是縮小了，運動中的時針是不是走得慢 些, $\mathrm{E}=\mathrm{mo}^{2}$ 是不是正確, 光在道空中速度是不 是一定，或者，光源底運動是不是有影響——逼 些問題，物理學應融來解决。如果物理研究的結 果對於我們似乎頗篇“奇怪”，與我們的根本概念 相矛盾，那察，我們便應當記起列密底學說，這些 研究結果沒有一個可以動搂唯物主義底基礎承認客觀現實，自然科學中遭樣的革命只合是狺 登法底證明。如果我們發現物理學家在物理理論 中追隨着唯心的觀點, 那我們就應該批評他, 根 㨜正確的誩證唯物主義的觀點指朋，這些概念在 科學方面是沼有根據的, 這些概念不但不能用事 蒉來加以論證，而且相反地，事䐝會駁倒它們。

在蘇聯早就泎朋白了, 爱因嘶坦在其折學結 战侖中表現了頗深的唯心的、馬赫主義的觀點。我
們德國的馬克思主義者，以及一切國度的馬克思 主義者，應該從造裹喛取敎訓。在我們德國的鳥 克思主義刊物中，不久以前還發表過把愛因斯坦

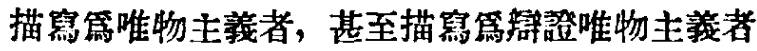
的交章。既然我們現在明白了，要因斯坦底哲學 觀點，特别是認䪭諭觀點是錯誤的，我們難道不 應該最低限度以批籼的謹㨁的態度對待他的在相 對論中表現出來的哲學觀點? 列德所不斷提醒的

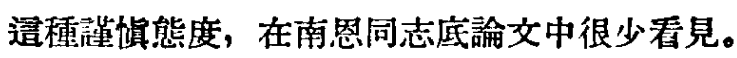
作者僅僅㴖足於指出愛因斯坦具有不少唯心主義 的疏泥, 指出在狹義相對論中有些問題還可以争 論，以及說明相對論也是相對的员理，還有待進 一步發展。

南恩同志自己也認第空間和運動底测定的相 對性，在愛因斯坦以前好久就已經認定了的。他 用了很多氣力來證明，逐種相對性與主觀性亚無

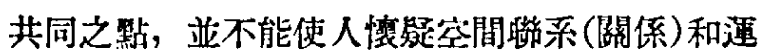
動底客觀性。無䝈地，放在車箱裹對於車箱馀來 是靜止的箱子，對於路基來說则是以一定的方式 運動着; 在火車中落下一物體, 對於車笪來說, 劃了一道鉛直線，對於路基來說，则是一條执 物線, 等等。特别無可爭論的是, 當沒份人挑選

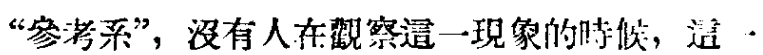
切也都客觀地在淮行。這一切都是對聯系以及相 對性的承認, 對於讋證法, 並不包含任们不可容 忍或非常的東西。

南恩同志引來作第證明的重量的例子, 當然, 是不合適的。一件物體在赤道上、在北極、在月 球上、在太隄上 ……具有不同的重量。但是一件 物體不能同時又在地球又在月婜上。然而，问一 做箱子，在車箱中是靜业的，京時又在運動。前 一點是對車箱來說, 後一點足對路基來說。並且, 同一偑箱子，在同一時間內，對於以太陽第基淮 
的胗考系來說, 则作了完全另樣的, 極第複雜的 蓮動。十分明顯，㯰一切都是客觀事渱，與主體 是否選摆了任意的參考系，以及定否有人來確認 這些事實並不相干。

但是, 所討論的不是關於這些不言自明的事 物的問題, 而完全是另外一些問題。所討論的是, 空間和運動底這種無可爭論的相對性, 是不是包 含有, 應不應輆包含有絕對的因素, 是不是與絕 對空間和絕對時間底存在不可避免地有所聯系。

如果相對論認篇，我們對於空間和運動的一 切测定都是相對的，那宏它是對的，而這些測定 並不因而裂失其客觀性。但是相對論說得更多, 它否認任何絕對空間與絕對運動。在逻裹它隐入 了唯心的相對主義。它認第空間和連動只是相對 的，它用相對性局限了自己的空間、運動概念。 因此必須記任列蜜底宎才指示，證法 “包含着 相對主義、否定、懹筑主義底契機，可是並不歸 綃黨相對主義”(1)。

我們看見了，列寧關於相對眞理與絕對焦理 的關係的哲學學說, 不僅可以應用到我們所談的 問題底物理方面來，而且還提供解决這個問題的 鍮匙。每一话連動都照相對的，遻就是說，它對 於不同的寥考系具有不同的性質。但是，每一個 運動同特又是絕對的運動，這就是說，是相對於 絕對室間的運動。認第絕對空間與絕對時間概念 沒有意義, 涊第它並不適應於客觀現實, 因篇不 可能知道這佩絕對空間，不可能確定和描述絕對 運動, 這種看法是不可知論、馬赫主義、相對主 莪。

恩格折早就確定了，空間和時間不是空虚的 “容器”，不是存在於物質之外，與物質脫離的某 種東西, 而是物質存在底形式。從而, 絕對空間 不能以造種調和的方式來了解。宇宙是物質的, 它佔有無筑的空間。這倠空間客觀存在着, 就是

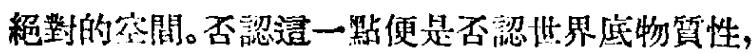
否認世界底客觀作存。每一话運微都是相對於逼 一絕對空間的絕對運動。沿有這话絕對空間，各 调物體便不能變更他在世界空間中的相互關聯的 位造，因面相對運動也不能存在。相對運動存在 遭一件事賽就不可反駁地證明了絕對空間和絕對 運動底保在。

任何一倜不願意脚下沿有科學根據的唯物主
義者都不能否認, 隹在着在空間摭展開來的字宙, 即字宙空間。這做字宙空間不可能不是絕對宾間, 因篇在這榈空間之外, 什密也不你在, 它不可能 淮入某润包括它自己在內的體系。递倜空間中的 一切物質都處於永恒浭動中，但是它們只可能在 道個宇宙空間中運動，說什整整㑉宇宙空間底通 動是沒有意義的。

愛因斯坦從馬赫那裹接受了否認絕對空間的

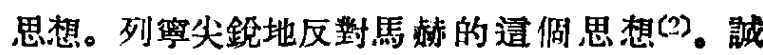
然，造一批制是針對馬赫的否認客觀空間的。但 是, 我們可以想到, 列蜜看出了否認絕對空間中 包含了否認客觀空間, 而且,列宜所批判的馬浾底 観黑點，在愛因斯坦的對於空間的認裁論概念底形 成中起了一定的作用。

甚至只討論相對運動的時候，參考系底選濹 也不能是任意的。說什空讨撃之後, 砲彈靜止砲 身㚣開，是沒有意義的。這就是說不能認第運動， 無非是物體相互位㯰變化，任何物體都可以看作 是靜止的。㗂該注意，運動和位造禁化具有自己

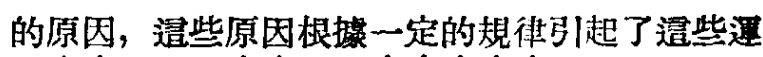

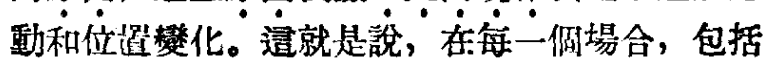
在相對测定的場合, 都應該區别那一偑在運動, 那一個“靜止”，如果火車在走，我便不能說火車 “静止”, 而鐵路路基對於火車而運動。飪該說，火 車對於鐵路路基而運動，因篇蒸汽底力量當然不 能使整個地球運動。賞然，這個谽法也只是相對 真實的，因篇我們捨開了地球繞自身之軸以及稿 太陽而作的運動，等等。但是这一切運動都具有 自己的原因，因此我們不能說恒星繞地球而喠，太 陽沿黄道而運動。

隨着科學之日谷精確地確定和考察到運動底 原因，我們便可以日谷接近於認識絕對運動。從 而, 說運動只是相對於某種參考系而確定的, 是 正確的。但是, 說任意的參考系都可以用, 便不 正確了。假如我選摆一滴雨水或一顆電子作第寥 考系，並且相對於遗一參考系來抬述傕動，那密， 這種描寫與宇宙的實際的運動毫無任 何共同之 點，因篇亚涊有造種力量、造種原因來引起遭種 164頁。

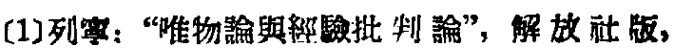

(2) 考列察: “唯物論與經瞼批判論”, 解故社 殿, 203-215頁。
3 月號
科學通報 
通動。

南恩同志說，趛種拈述之無意義，是因篇電

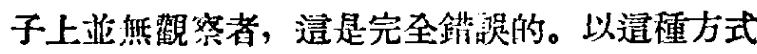

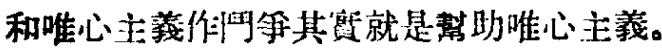

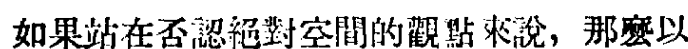
一顆電子篇基準的參考系是可以用的。只有唯心 主義者才能流汥有被觀察到的束西是不存在的東

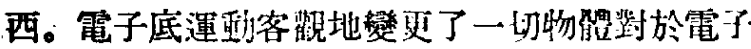
的位置，這與電子上面有沒有觀察者是全無關係 的.

南恩同志所作的造種論證，反朑了唯心主義 的觀點。根接否認絕㠚空間的觀點，可以也應該

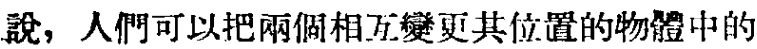
任意一话看作是静止的。從因果觀點看來，便不 能馀，掉下去的鉛筆是“静止”的，屋子相對於鉊 筆而向上運動。再回到前面的例子。我們可以 說，車箱中的箱子對於車箱是静止的，而對於地 球、太陽、恒星等等则進行着不同的蓮動。但是 不能說，地球、太陽、恒星在以箱子第基準的寥 考系中相對於箱子而作運動。再者，觀察者雖 然不能坐在電子上, 却可以坐在兽倜箱子上。如

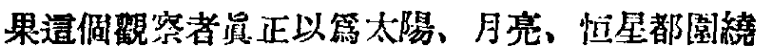

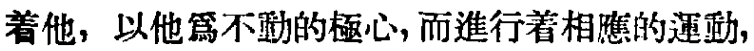
那他就會是一榈㾘子。因果観點與承涊相對運動 （火車對於地球而運動）是相容的，但與否認絕 對空間是不相容的。相對運動客觀地决定於相應 的原因，而不是决定於參考系的任意選摆。

相對論認第，運動中的時鉝此“静止”的時鐘 走得慢。這種論斷只能激䗌形而上學者, 但不能 激動詩證法者。運動是現望的物質過程，正如每 一個物質過程一樣, 它要起一種作用。這些作用 性質如何的問題之提出，及其說明，是物理觀察 及其理論處理底對象。運動是不是縮小了物體底 長度, 是不是堆大了物触底質量, 是不是延綏了 時鉝底行進一一造些是純粹的物理問題。

但是, 如果把時期行進底綬慢了解篇時間本 身淮程底緩慢，如果隨着否認絕對空間一逍否認 紹教特間，那問題就不同了。這時就發生了哲學 認識論的問題，應該根接譬登唯物主義觀點來確 定對逜润問題的看法：存在不存在絕對的時間?

關於這偑重要的問題, 南恩同志除了引用了

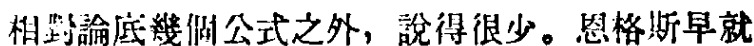
規定了，時間也是物質存在底形式，換言之，即時 間是與物質過程相聯的。但是，恩格听反對了從

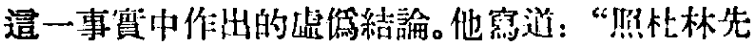
生意見，時間只是經渦戀化而存在，而不是變化 經過時間而存在。正是因篇時閏是和變化不阔的, 是對它猡立的，所以時間可以用督化水测量，因 在测量某物時, 總是需要一種與所测之物不京的 東西. 再次，在其經過中汥有㡎生任何䫏苦缶化 的時間，絕非完全不是時間，反之，这正是純粹 的，汥有被外部混合物所淩雜的時間，因之近就 是真望的呩間，原來的畤間。事望上，我們如果 要設想一種完全純粹的，與一切不相于的外部混

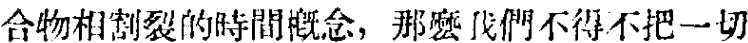

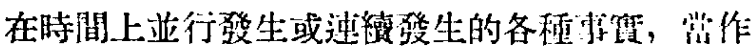
與此焎關的東酒，換们話說，我們荘没想一想其 中汥有發生任何事情的時問，那㭙，我們不使時 間的概念沉汥於一般的存在的慨念之中，而酿是 這樣地到達於一種純粹的時間的概念”(1)。

逜是不是說，恩格斯在這要拒絕了把封問看 作物質存在形式的觀點呢? 完全不是。如果汥有 物質和物質過程，便浔有時問。但是，筑了提仕 純粹的時間概念，如恩格斯所說的，我們應該從 在時間中發生的具栺過程中抽象出桃。

可不可以馀，恩格斯底意見已經老鼠了，被 現代物理底結論駁倒了? 不。让是在今天，常介 圆利用相對論来創造唯心的時間概念的詩候, 它

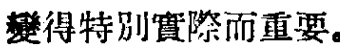

如果了解了找僻在上一段中所的，在運䣦

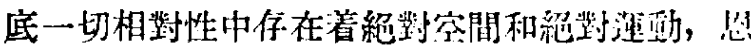
格斯底意見底止確性便很容易看出來了。相對詥 中, 時間底相對性與運動底相椡性密切相關。如 果存在着絕對空間與絕對運動，那㦄一定世存在 着與之相適應的絕對時間，局限於只承涊相對捗 間是不可能的。

還有一倾問題，在这话問題上，相對諭底涊 識論原則底唯心特點表現得極篇朋䫏，這就是對 於同時性問題的看法。

當阔述相對論的時候, 常常從這樣一種不可 知論的主題出發，說什璴不可能精確地確定正雨件

(1)恩格斯: “反杜林論”，三聯版，55--56面。 
在空間上互相隔開了的事件是否同時發生。第 不存在比光速更大的速度, 於是固有的蓮動只能 相對地测定，预篇同時性底测定設立了一個不可 踰越的極限。根據這種實證主義的論綱, 相對諭 便作出了結論說，沒有什麼别的，無非是“同意” 而巳。這就是說, 可以在一定的程度上任意規定 同時性應該如何了解，正如任意規定質量單位一 樣(後者自然是正確的)。這樣, 相對論便得出了 它的著名定義: 丽眖事件是同時的, 如果從它們 兩處發出的光同時到達某一距兩處等遠的點的 話。

受因斯坦自己公開表示過，這個定義具有一 定程度的任意性。他的有些捥護者害怕這储公囬 的承認, 說在這倜定義中並沒有任何任意性, 因 篇苟克棌實驗所證明的光速底不變性, 需要䢜種 對於同時性的解釋。但是這是詭讋，如果受因斯 坦並沒有㯰種必要的話, 他當然也不會承認這種 任意性的。篇了一般地討諭確定的速度或不傩的 速度, 需要以同時性概念篇前提. 只有確定了什

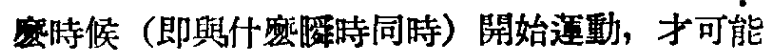
㓭到連動到達一定點之前繼纕了多久，談到運動 底速度有多大。

不能把同時性底定義與使我們有可能確定同 時性的方法混篤一談. 愛因斯坦的定義項多可以
作䉆一種尺度，來度量某件事是不是同時的，但 是它亚汥有說到造種同時性是什㦄。唯物論者不

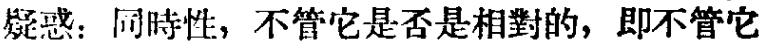
热否依赖於參考系，在任何場合下，都是客觀的 閵係，這種客觀關係並不管我“想”把同時性“衣

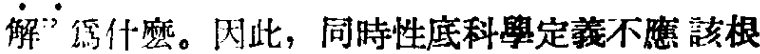

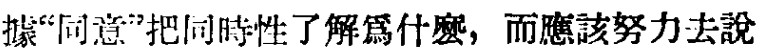

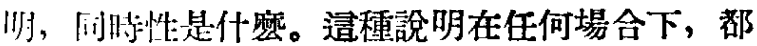
员:必需的。舜因断坦說, 不能滿足于這種回答, 似乎大家都很懂得“同時”是什麼意思, 這一點他 是完全對的。但是, 當他要求同時性概念定義中 要色含如何規定兩佔事件是否實際上同特的方法 時, 他是錯了。我們可以說明關於百億年前發生的 某件事物的概念, 那怕我們不知道要用什麼方法 米確定它。同時性(客觀)存在着的問題, 與我如 何检登、規定网個事件底同時性的問題，是互相 極篇深到地聯系着的，但又不是完全等同的。伤 論在任何場合都不能馀，同時性的意密可以依我 們的䝠㘹而任意選擇。即使像相對諭中那樣作一 话保留條件，即這種任意性不應該與貿驗相矛 盾，㯰也是不能容部的。

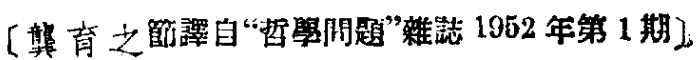

